Supplementary Information

\title{
Electrolyte Reactivity in the Double Layer in Mg Batteries: An interface potential-dependent DFT Study
}

\author{
Anja Kopač Lautar ${ }^{1,2}$, Jan Bitenc ${ }^{1}$, Tomaž Rejec ${ }^{2,3}$, Robert Dominko ${ }^{1,4,5}$
} Jean-Sébastien Filhol*, ${ }^{6,7}$ Marie-Liesse Doublet ${ }^{6,7}$

${ }^{1}$ Department of Materials Chemistry, National Institute of Chemistry, Slovenia ${ }^{2}$ Department of Physics, Faculty of Mathematics and Physics, University of Ljubljana, Slovenia ${ }^{3}$ Jozef Stefan Institute, Ljubljana, Slovenia

${ }^{4}$ Faculty of Chemistry and Chemical Technology, University of Ljubljana, Slovenia ${ }^{5}$ ALISTORE-ERI, FR3104, 80039 Amiens cedex, France

${ }^{6}$ Institut Charles Gerhardt, CNRS \& Université de Montpellier, Place E. Bataillon, France ${ }^{7}$ RS2E French network on Electrochemical Energy Storage, FR5439, Amiens, France *Corresponding author: Jean-Sébastien Filhol (jean-sebastien.filhol@umontpellier.fr) 
S1. Computational Details. Periodic DFT calculations were performed using the Vienna Ab Initio Simulation Package $(\text { VASP) })^{1,2}$ within the generalized gradient approximation (GGA) using $\mathrm{PBE}^{3}$ functional for exchange and correlation potential and projector augmented wave pseudopotentials $(\mathrm{PAW})^{4}$ with a cut-off energy of $450 \mathrm{eV}$. Long-range electrostatic interactions between interfaces arising from periodic boundary conditions were avoided by building a symmetric unit cell. The electrode surfaces were modelled with a 5-layer symmetric slab of $\mathrm{Mg}(0001)$ surface in a (5 x 5) supercell. One $\mathrm{Mg}^{2+}$ solvated cation with explicit solvent molecules or a free solvent molecule was added at each side of the slab (Fig. 1, supplementary cif information) symmetrically at a distance of $9 \AA$ from the surface. This ensured a homogeneous charging of both sides of the slab for the electrochemical calculations to coherently extract the energetic of the charge interfaces and no dipole correction is needed. The interslab distance between periodic surfaces was set to $40 \AA$ and an implicit solvent was added by means of a Polarizable Continuum Model (PCM) as provided by VASPSOL. ${ }^{5,6}$ The PCM is parameterized with the solvent dielectric constant. The chosen values for dielectric constants are the experimental values in the studied electrolyte, i.e. $\varepsilon_{r}=7.20$ for DME and $\varepsilon_{r}=89.9$ for EC system. It has been shown previously that the dielectric constant affects the differential capacitance: the capacitance is small for small dielectric constant, whereas for larger dielectric constants the capacitance increases and becomes stable. ${ }^{7}$ The average capacitance in our case was $3 \mu \mathrm{F} / \mathrm{cm}^{2}$ for $\mathrm{Mg}(\mathrm{DME})_{3}$ and $6 \mu \mathrm{F} / \mathrm{cm}^{2}$ for $\mathrm{Mg}(\mathrm{EC})_{6}$. The cavity size is defined by an electronic density cut-off parameter, which has similar impact on capacitance as the dielectric constant. ${ }^{7}$ The density cut-off parameter was determined as $2.5 \times 10^{-5}$ for the studied systems. The Brillouin zone integration in k-space was performed on a $4 \times 4 \times 1 \mathrm{k}$-point grid. Structural relaxations were performed on all atoms except the central Mg-slab layer, which was kept frozen to bulk parameters. The residual forces after structural relaxation were lower than $0.01 \mathrm{eV} / \mathrm{A}$. Due to the large vacuum layer allowing a clear-cut separation between surface and cation, the surface and solvated cation charges were obtained by direct electron density grid integration. Note that when adding implicit solvation model to electrochemical calculations, the interslab distance has negligible effect on the differential capacitance. ${ }^{7}$

The free electrochemical energy of an interface $F$ can be obtained from the potential dependant Gibbs free energy $G(V)$ of the electrochemical system by the relation : $F(V)=G(V)-N_{e} \mathcal{F} V$, where $N_{e}$ is the number of excess electrons relatively to surface neutrality, $V$ the applied potential and $\mathcal{F}$ is the Faraday constant. ${ }^{7-11}$ In these calculations, we neglect the temperature effect over the potential effect, thus $G(V) \approx E(V)$ with $E(V)$ being the potential-dependent energy. Due to the use of the homogeneous background that compensates for the charge in this electrochemical approach a correction for the homogeneous background of the computed DFT energy $E_{D F T}(V)$ is needed. The potential dependant energy is then given by:

$E\left(N_{e}\right)=E_{D F T}^{0}+\frac{d_{0}}{d}\left(E_{D F T}\left(\left(N_{e}\right)-E_{D F T}^{0}+e \int_{0}^{N e} V_{a}(N) d N\right)\right.$ with $E_{D F T}^{0}$ being the DFT energy computed at zero charge, i.e. for $N_{e}=0, e$ the elementary charge, $V_{a}$ the average potential in the unit cell, and $\frac{d_{0}}{d}$ the fraction of vacuum in the unit cell. ${ }^{10}$ The potential dependence of free electrochemical energy resembles an inverted parabola with potential of zero charge being the maximum of the parabola. The curvature of the parabola is closely connected to the differential capacitance: $C=-1 / S\left(\partial^{2} F / \partial V^{2}\right)$. 
Potential relatively to vacuum is directly extracted from the calculations for each charged system by direct calculation of the Fermi level position relatively to the vacuum reference. The SHE scale is obtained from the vacuum scale by using: $V_{S H E}=V_{\text {vacuum }}-4.5$.

S2. Experimental Details. All the electrochemical measurements were performed in a 3-electrode setup. Due to the fact that carbonate solvents passivate $\mathrm{Mg}$ metal, ${ }^{12}$ we decided to use high surface area carbon electrode as a reference electrode instead of more commonly used Mg metal. Our high surface area carbon (Printex carbon) electrode had a potential of $2.11 \mathrm{~V} / \mathrm{Mg}$ metal consistent with earlier report, where such high surface area carbon reference electrodes were utilized. ${ }^{13}$ High surface area electrode was composed of $75 \%$ of Printex carbon black and 25\% of PTFE binder. Use of high surface area carbon reference electrode was validated by measuring cyclic voltammogram in $0.4 \mathrm{Mg}$ (TFSI)2 in DME with conventional setup (Pt working electrode, $\mathrm{Mg}$ metal as reference and counter electrode), which yielded equivalent electrochemical response (Fig. S9) as in case of carbon reference electrode. Mg metal was brushed with P1000 brush paper just before assembly inside the glove-box. Diameter of working electrode was $10 \mathrm{~mm}$. 


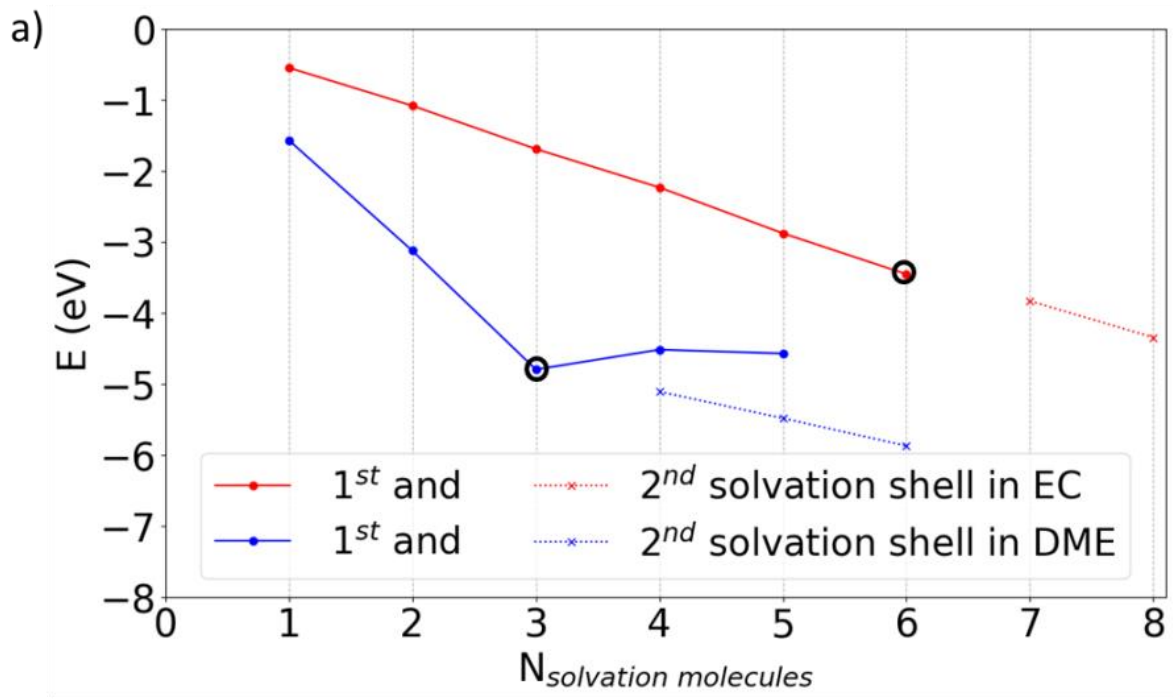

b)

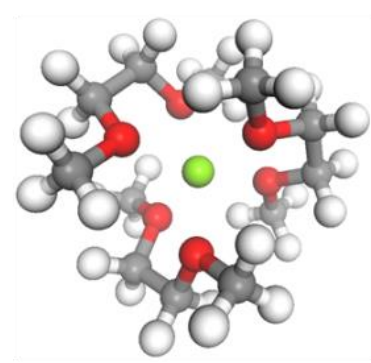

c)

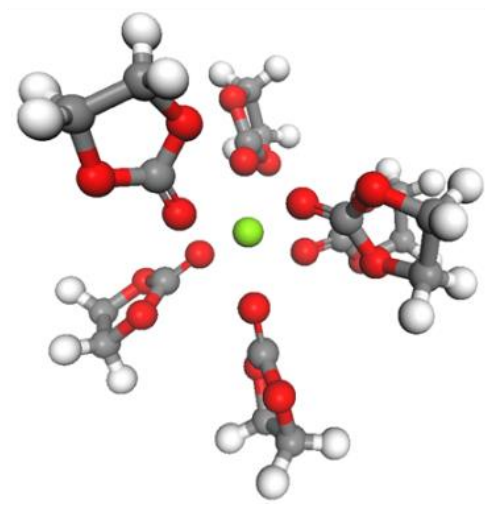

Figure S1. Determination of the first solvation shell of $\mathrm{Mg}^{2+}$ in DME and EC solvent. (a) The calculated DFT energy for $\mathrm{Mg}^{2+}$ solvated with different number of DME (blue) and EC (red) molecules. The energetic minimum defines the most probable first solvation shell in a specific solvent, marked in graph with a black circle: (b) $\mathrm{Mg}^{2+}$ solvated with three DME molecules and (c) $\mathrm{Mg}^{2+}$ solvated with six EC molecules (optimized geometry from DFT Gaussian calculations). In both cases, the $\mathrm{Mg}^{2+}$ coordination is six. 
a)
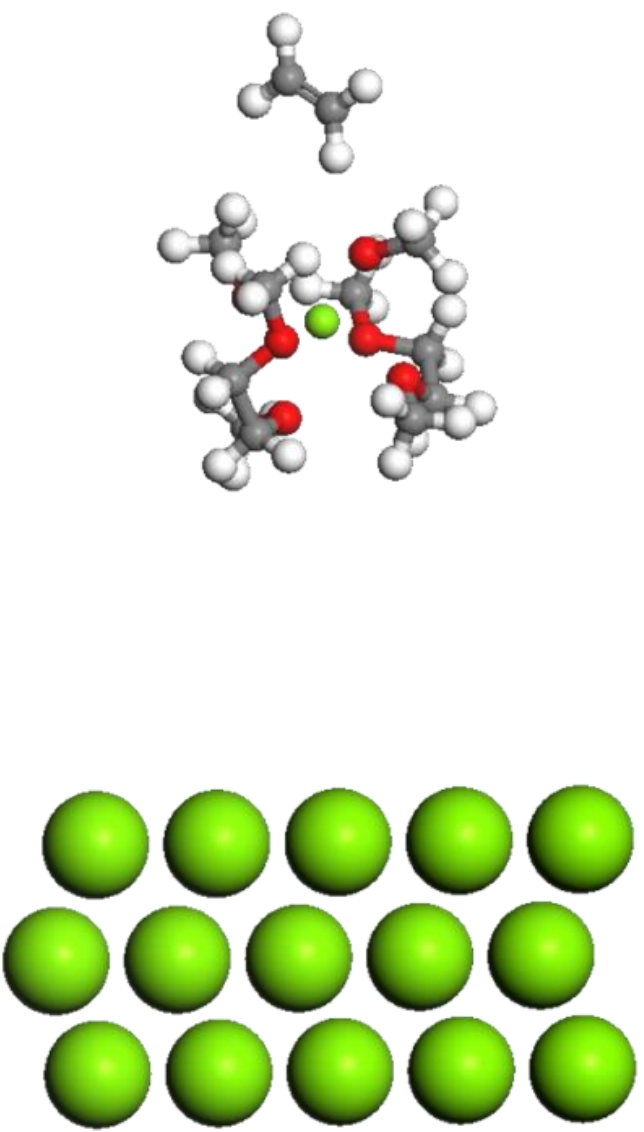

b)
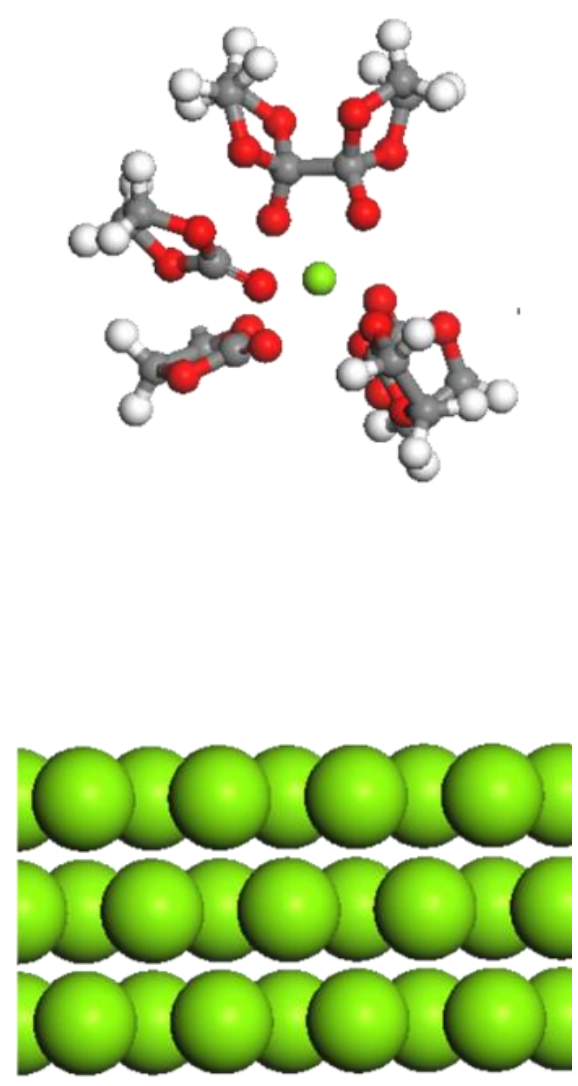

Figure S2. Spontaneous reduction of $\mathrm{Mg}^{2+}$ solvation shell. (a) Fragmented product from $\mathrm{Mg}(\mathrm{DME}) 3^{2+}$ system after spontaneous reduction: one DME molecule dissociates into two methanolate ions $\left(\mathrm{CH}_{3} \mathrm{O}^{-}\right)$and one ethylene molecule $\left(\mathrm{C}_{2} \mathrm{H}_{4}\right)$ to form the neutral $\mathrm{Mg}\left(\mathrm{OCH}_{3}\right)_{2}(\mathrm{DME})_{2}$ complex. (b) Dimer derived from $\mathrm{Mg}(\mathrm{EC})_{6}{ }^{2+}$ after spontaneous reduction: two $\mathrm{EC}$ molecules dimerize to form the neutral $\mathrm{Mg}(\mathrm{EC})_{4}($ dimer) complex. 


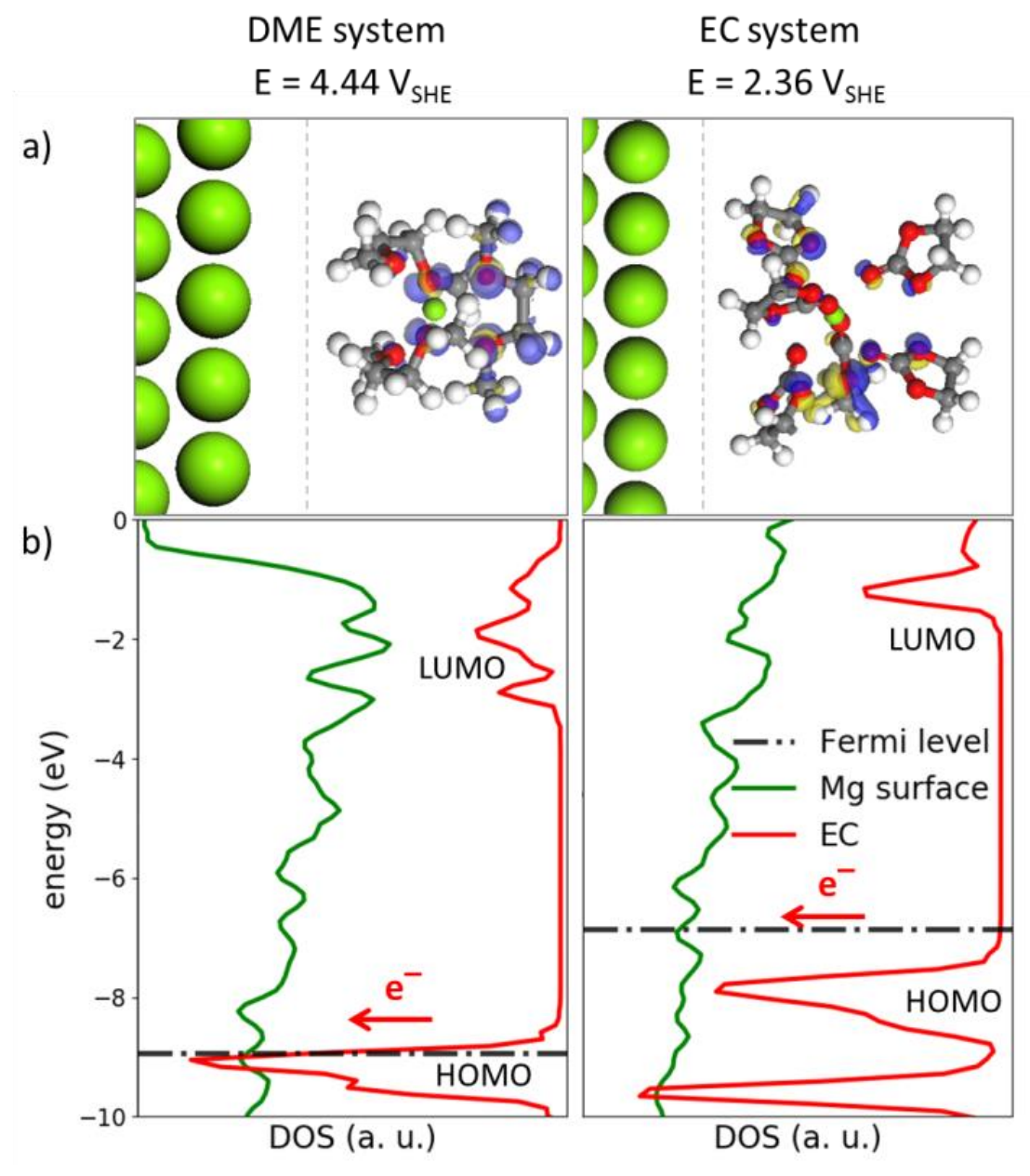

Figure S3. Chemical descriptors of the DME and EC solvent reactivity. (a) Fukui functions computed for the $\mathrm{Mg}_{\mathrm{s}} /$ $\mathrm{Mg}(\mathrm{DME}) 3^{2+}$ oxidized interface at oxidative potential (4.44 $\mathrm{V}_{\mathrm{SHE}}$ ) (left) and for the $\mathrm{Mg}_{\mathrm{s}} / \mathrm{Mg}(\mathrm{EC}) 6^{2+}$ oxidized interface at oxidative potential (2.36 V SHE) (right). The positive contribution of the Fukui function (blue volumes) allows identifying the redox centre of the electrochemical reaction (reduction or oxidation). Fukui function at the oxidative potential shows that the electrochemical activation of both $\mathrm{Mg}(\mathrm{DME})_{3}{ }^{2+}$ and $\mathrm{Mg}(\mathrm{EC}) 6^{2+}$ takes place through oxidation of the oxygen lone-pair states, which is in perfect agreement with the well-known oxidation/peroxidation of glymes. ${ }^{14-16}$ Note that the empty space between the surface and the solvated species was decreased for sake of visualization. (b) Projected density of states (PDOS) on the surface (green) and on $\operatorname{Mg}(\mathrm{DME}) 3^{2+} / \mathrm{Mg}(\mathrm{EC})_{3}{ }^{2+}$ (red) at oxidative potential. The main effect of the potential is to decrease the Fermi energy with respect to the vacuum reference. Consistently, a shift of the Fermi level down to the $\operatorname{HOMOs}$ of $\mathrm{Mg}(\mathrm{DME}) 3^{2+}$ and $\mathrm{Mg}(\mathrm{EC})_{6}{ }^{2+}$ is observed, and induces an electron transfer from the solvated species to the $\mathrm{Mg}$-surface.

All energies are referenced relatively to the vacuum level. 


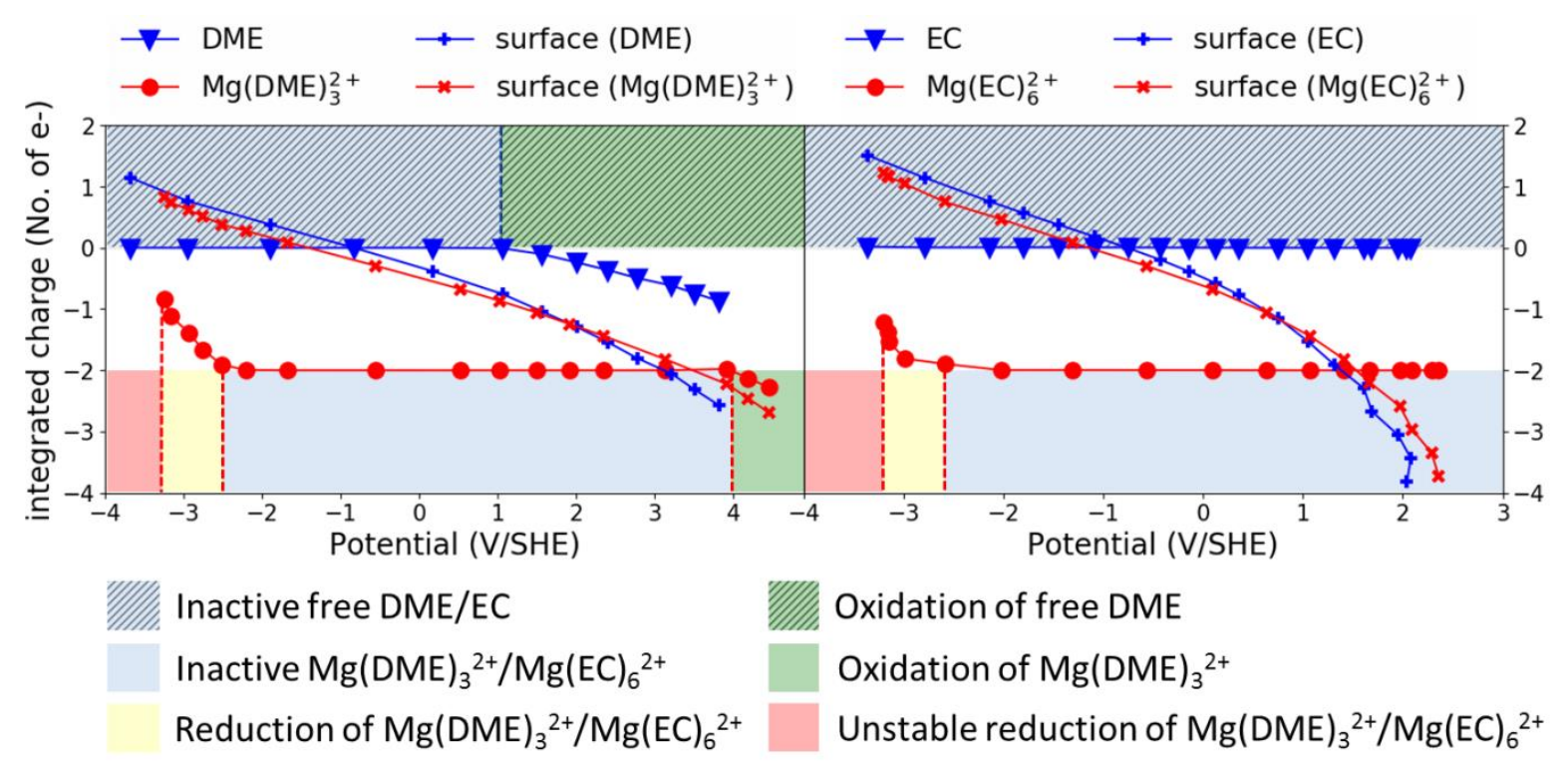

Figure S4. Potential-dependent thermodynamic stability of DME- and EC-based electrolytes and free DME and EC solvent molecules. Potential dependent net charge computed on the surface and on the solvated $\mathrm{Mg}$ or free solvent molecule for (left) DME and $\mathrm{Mg}(\mathrm{DME}) 3^{2+}$, and for (right) free $\mathrm{EC}$ and $\mathrm{Mg}(\mathrm{EC}) 62+$ system. The solvent molecule coordinated to $\mathrm{Mg}$ starts gaining electrons (i.e. starts to be activated by electron transfer) at approximately -2.5 VSHE and -2.7 VSHE for the DME and EC system, respectively. However, free EC and DME solvent molecules (not coordinated to $\mathrm{Mg}^{2+}$ ) show high electrochemical stability down to very low potentials $(-4 \mathrm{VSHE})$ in agreement with their LUMO remaining far above the $\mathrm{Mg}^{2+} / \mathrm{Mg}^{0}$ redox energy (Figs. S5b and S6b). Free EC is shown to be kinetically stable (no electron transfer) in oxidative conditions, as well, up to 2-2.5 $\mathrm{V}_{\text {SHE }}$ which justifies the wide use of alkyl carbonates in the battery technology (Fig. S6). In contrast, free DME is sensitive to oxidation above $1 \mathrm{~V}_{\text {SHE }}$ due to the activation of its oxygen lone-pairs which raises the HOMO orbital far above the $\mathrm{Mg}^{2+} / \mathrm{Mg}^{0}$ redox potential (Fig. S5) hence leading to a possible DME oxidation / peroxidation at higher potentials. ${ }^{14-16}$ 


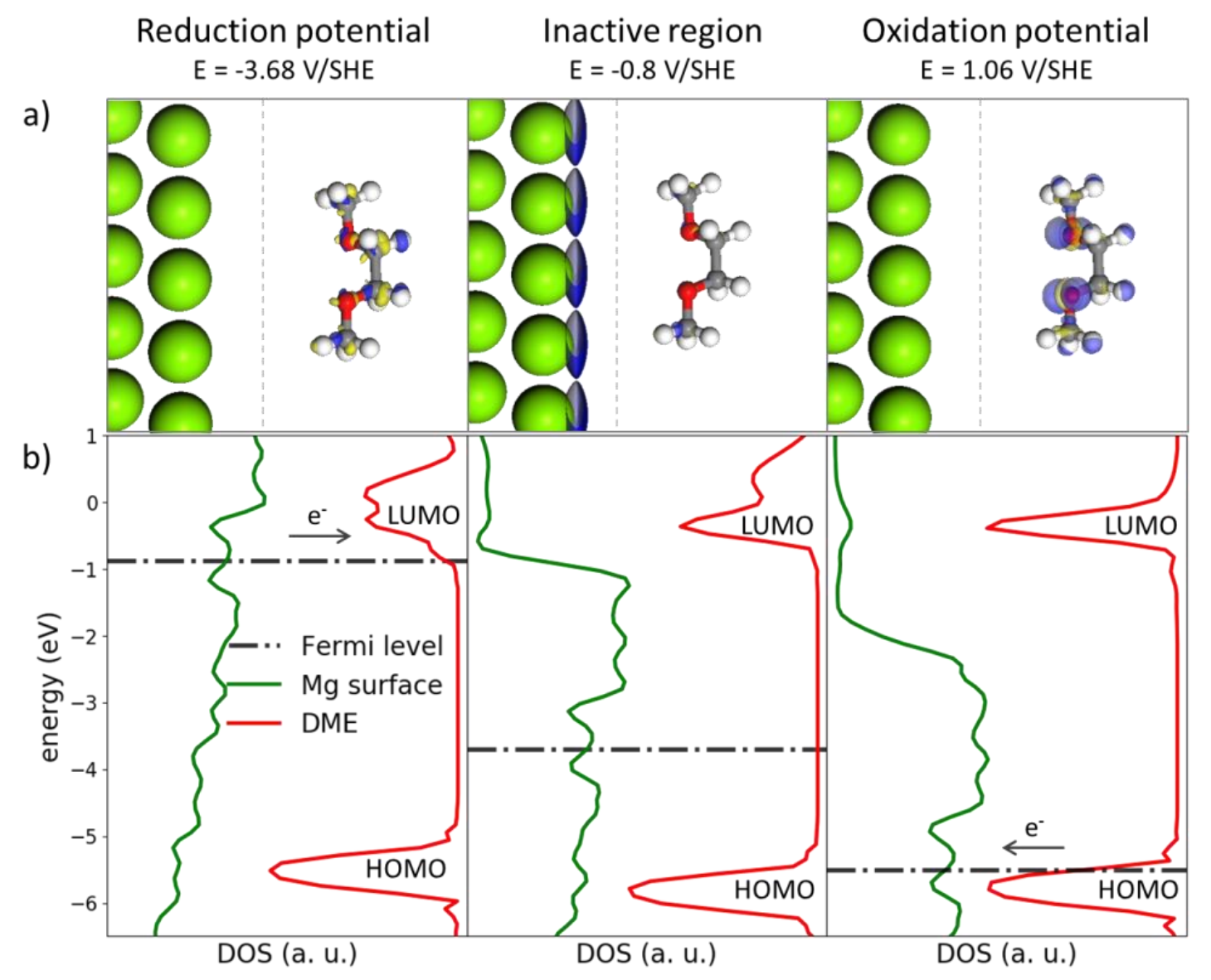

Figure S5. Chemical descriptors of the free DME solvent molecule reactivity. (a) Fukui function computed for the $\mathrm{Mg}_{\mathrm{S}} / \mathrm{DME}$ oxidized interface at reduction potential (-3.68 $\left.\mathrm{V}_{\mathrm{SHE}}\right)$, inactive region (-0.8 $\left.\mathrm{V}_{\mathrm{SHE}}\right)$, and oxidation potential (+1.06 $\mathrm{V}_{\mathrm{SHE}}$. The positive contribution of the Fukui function (blue volumes) allows identifying the redox centre of the electrochemical reaction (reduction or oxidation). Fukui function at the reductive potential and inactive region shows that the free DME molecule is stable. In the inactive region only the Mg-surface is activated. Fukui function at the oxidative potential shows that the electrochemical activation of free DME takes place through oxidation of the oxygen lone-pair states. (b) Projected density of states (PDOS) on the surface and on free DME molecule at all three potentials chosen for the Fukui function calculation. At the reductive potential the Fermi level approaches the LUMO of the free DME and electron transfer from Mg-surface to the DME could be induced by lowering the potential even more. In inactive region, the Fermi level is in the HOMO/LUMO gap, making electron transfer impossible. At the oxidative potentials, the Fermi level is shifted down to HOMO of free DME, which induces an electron transfer from the free DME to the $\mathrm{Mg}$-surface.

All energies are referenced relatively to the vacuum level. 


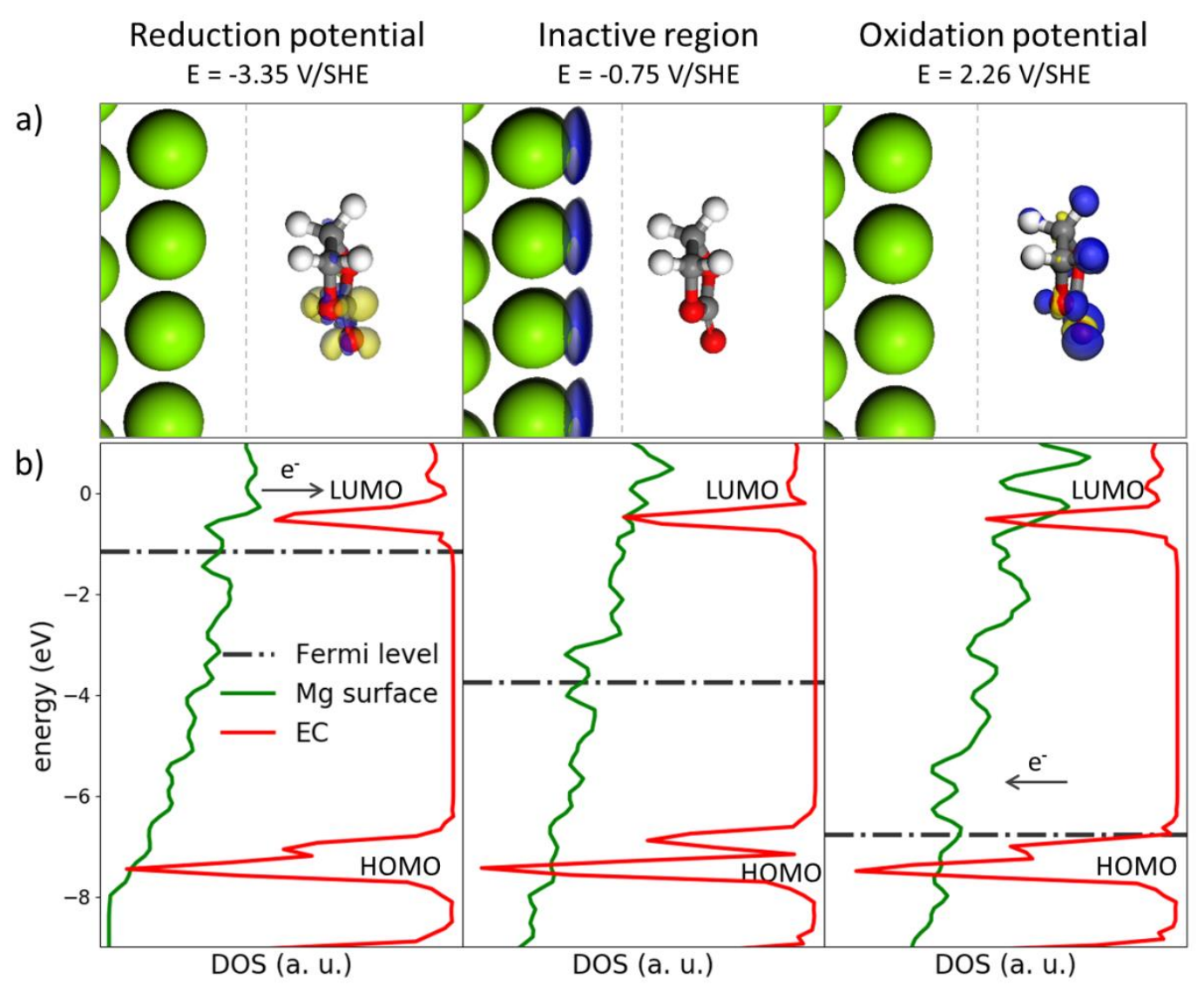

Figure S6. Chemical descriptors of the free EC solvent molecule reactivity. (a) Fukui function computed for the $\mathrm{Mg}_{\mathrm{s}} / \mathrm{EC}$ oxidized interface at reduction potential $\left(-3.35 \mathrm{~V}_{\mathrm{SHE}}\right)$, inactive region $\left(-0.75 \mathrm{~V}_{\mathrm{SHE}}\right)$, and oxidation potential $\left(+2.26 \mathrm{~V}_{\mathrm{SHE}}\right)$. The positive contribution of the Fukui function (blue volumes) allows identifying the redox centre of the electrochemical reaction (reduction or oxidation). Fukui function at the reductive potential and inactive region shows that the free EC molecule is stable. In the inactive region only the Mg-surface is activated. Fukui function at the oxidative potential shows that the electrochemical activation of free EC takes place through oxidation of the oxygen lone-pair states. However, this happens at highly oxidative potentials, and free EC molecule demonstrates electrochemical stability up to 2-2.5 VSHE. (b) Projected density of states (PDOS) on the surface and on free EC molecule at all three potentials chosen for the Fukui function calculation. At the reductive potential the Fermi level approaches the LUMO of the free EC and electron transfer from Mg-surface to the EC could be induced by lowering the potential even more. In inactive region, the Fermi level is in the HOMO/LUMO gap, making electron transfer impossible. At the oxidative potentials, the Fermi level is shifted down to HOMO of free EC. However, contrarily to free DME, free EC molecule is stable up to 2-2.5 $\mathrm{V}_{\text {SHE. }}$

All energies are referenced relatively to the vacuum level. 


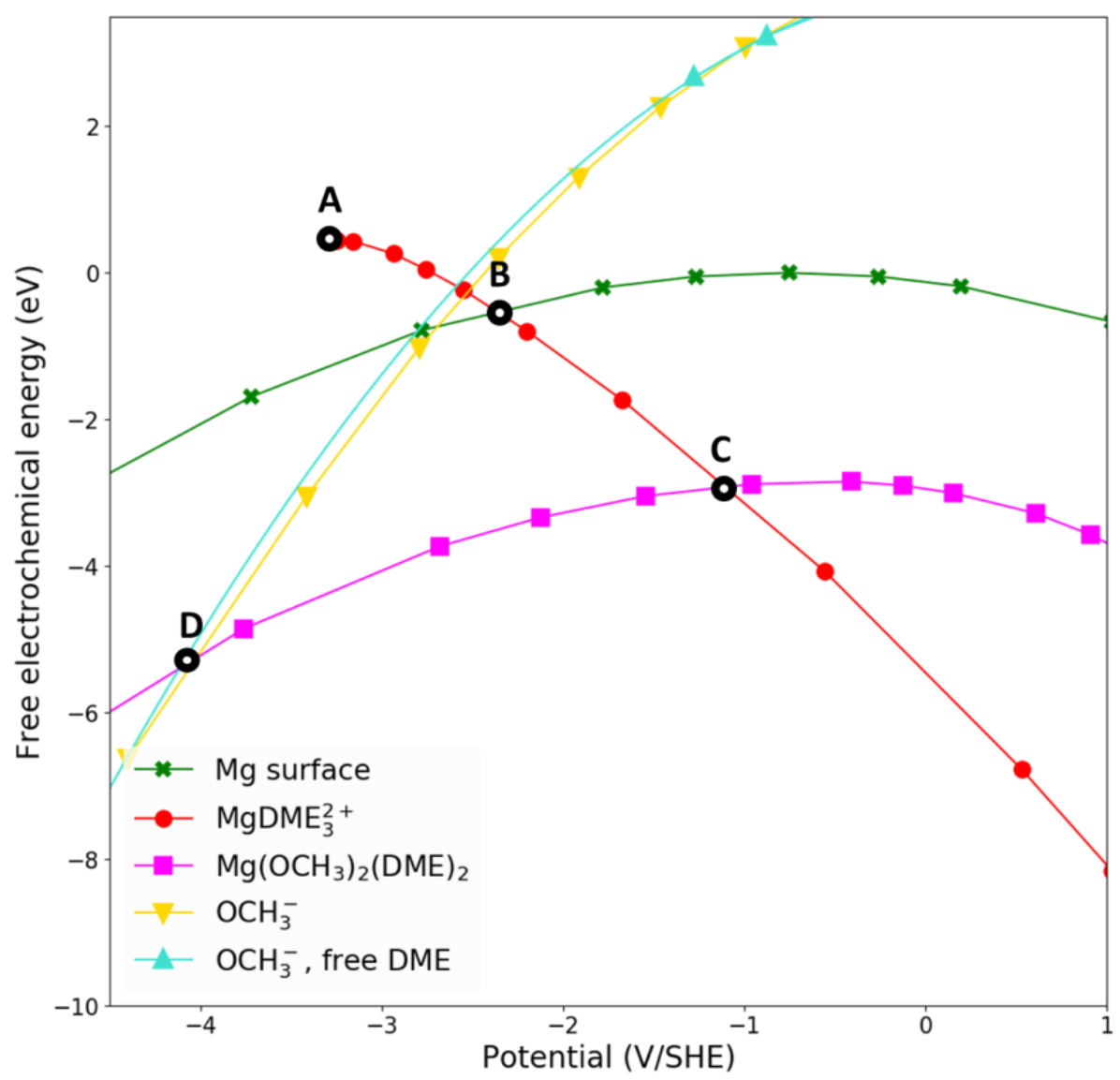

Figure S7. Potential dependence of free electrochemical energy for different system in monoglyme solvent. The letters mark potentials of importance: $\mathrm{A}$ - the initial solvated $\mathrm{Mg}$ complex (red) is completely reduced, and decomposed into $\mathrm{Mg}(\mathrm{DME})_{2}\left(\mathrm{OCH}_{3}\right)_{2}$ and free $\mathrm{C}_{2} \mathrm{H}_{4}$ (pink); $\mathrm{Mg}(\mathrm{DME})_{3}{ }^{2+}$ complex is unstable below this potential (spinodal limit); $\mathrm{B}-$ the equilibrium potential associated with $\mathrm{Mg}(\mathrm{DME})_{3}{ }^{2+} / \mathrm{Mg}^{0}$ redox pair; $\mathrm{C}-$ equilibrium potential of $\mathrm{Mg}(\mathrm{DME})_{3}{ }^{2+} / \mathrm{Mg}(\mathrm{DME})_{2}\left(\mathrm{OCH}_{3}\right)_{2}$ pair below hich the reduced $\mathrm{Mg}(\mathrm{DME})_{2}\left(\mathrm{OCH}_{3}\right)_{2}$ complex, becomes thermodynamically the most stable species; $\mathrm{D}$ - equilibrium potential of $\mathrm{Mg}\left(\mathrm{OCH}_{3}\right)_{2}(\mathrm{DME})_{2} / \mathrm{Mg}^{0}$ below which $\mathrm{Mg}\left(\mathrm{OCH}_{3}\right)_{2}(\mathrm{DME})_{2}$ is reduced into $\mathrm{CH}_{3} \mathrm{O}^{-}$and $\mathrm{Mg}^{0}$. This happens at very low potentials, at approximatelly -4 VsHe. This suggests that reduction reactions involving the formation of hard Pearson bases $\left(\mathrm{CH}_{3} \mathrm{O}^{-}\right)$are very unlikely. The reduction of DME in $\mathrm{Mg}(\mathrm{DME}) 3^{2+}$ thus leaves the $\mathrm{Mg}^{2+}$ trapped in the formed $\mathrm{Mg}\left(\mathrm{OCH}_{3}\right)_{2}(\mathrm{DME})_{2}$, as the latter is practicaly imposible to further reduce. Note that we computed the potential of reduction of $\mathrm{Mg}\left(\mathrm{OCH}_{3}\right)_{2}$ (DME) $)_{2}$ to $\mathrm{CH}_{3} \mathrm{O}^{-}$and $\mathrm{Mg}^{0}$ using two different models: only $\mathrm{CH}_{3} \mathrm{O}^{-}$in front of the surface and $\mathrm{CH}_{3} \mathrm{O}^{-}$and a free DME molecule in front of the surface (Fig. S8). Both give approximatelly the same result (letter D). 
a)
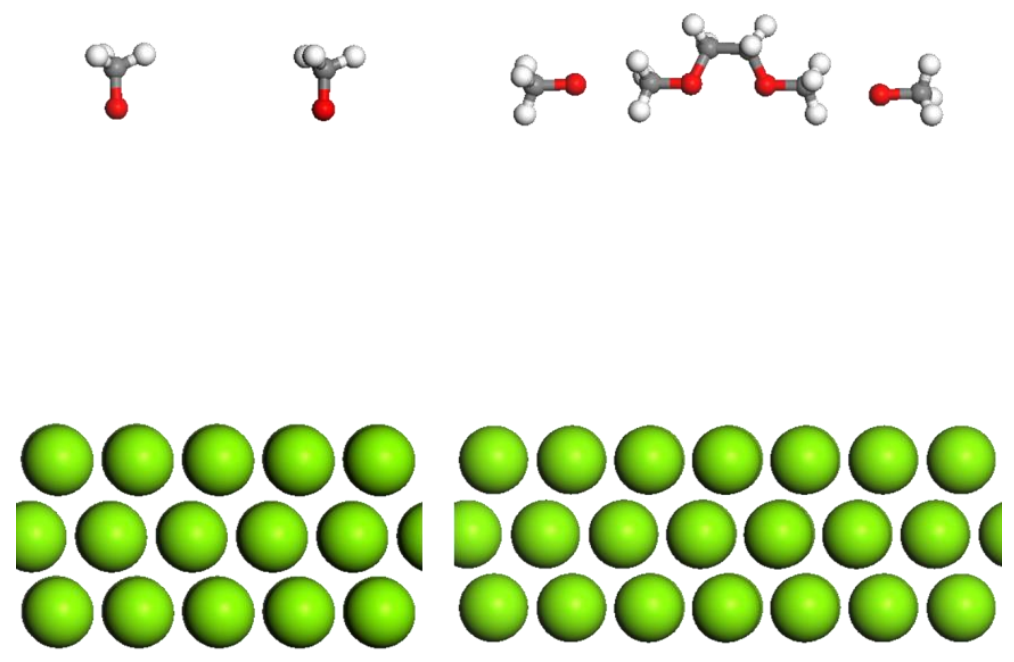

Figure S8. Models for calculating the reduction potential of decomposed $\mathrm{Mg}^{2+}$ solvation shell in DME. To calculate the potential of reduction of $\mathrm{Mg}\left(\mathrm{OCH}_{3}\right)_{2}(\mathrm{DME})_{2}$ to $\mathrm{CH}_{3} \mathrm{O}^{-}$and $\mathrm{Mg}^{0}$ two different models were used: (a) only $\mathrm{CH}_{3} \mathrm{O}^{-}$in front of the surface and (b) $\mathrm{CH}_{3} \mathrm{O}^{-}$and a free DME molecule in front of the surface. Both give approximatelly the same result (Fig. S7, point D).

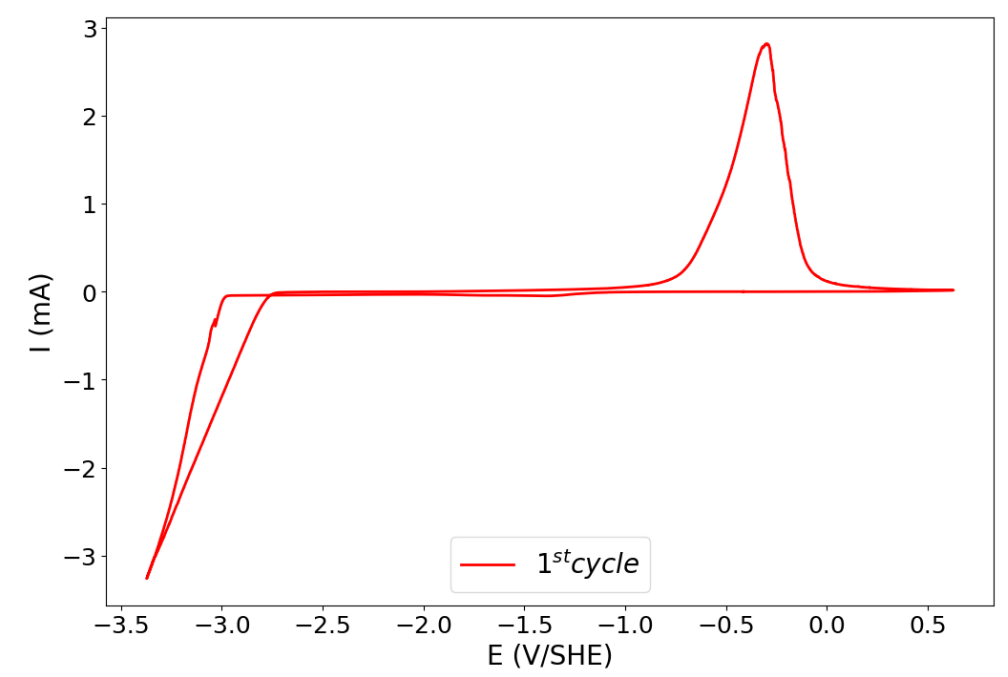

Figure S9. Cyclic voltammetry on Pt working electrode. Cyclic voltammetry on Pt working electrode in $0.4 \mathrm{M} \mathrm{Mg}(\mathrm{TFSI})_{2}$ in DME with sweep rate of $25 \mathrm{mV} / \mathrm{s}$. Both counter and reference electrode were $\mathrm{Mg}$ metal. 


\section{References}

(1) Kresse, G.; Furthmüller, J. Efficiency of Ab-Initio Total Energy Calculations for Metals and Semiconductors Using a Plane-Wave Basis Set. Comput. Mater. Sci. 1996, 6 (1), 15-50. https://doi.org/10.1016/0927-0256(96)00008-0.

(2) Kresse, G.; Furthmüller, J. Efficient Iterative Schemes for Ab Initio Total-Energy Calculations Using a Plane-Wave Basis Set. Phys. Rev. B 1996, 54 (16), 11169-11186. https://doi.org/10.1103/PhysRevB.54.11169.

(3) Perdew, J. P.; Burke, K.; Ernzerhof, M. Generalized Gradient Approximation Made Simple. Phys. Rev. Lett. 1996, 77 (18), 3865-3868. https://doi.org/10.1103/PhysRevLett.77.3865.

(4) Kresse, G.; Joubert, D. From Ultrasoft Pseudopotentials to the Projector Augmented-Wave Method. Phys. Rev. B 1999, 59 (3), 1758-1775. https://doi.org/10.1103/PhysRevB.59.1758.

(5) Fishman, M.; Zhuang, H. L.; Mathew, K.; Dirschka, W.; Hennig, R. G. Accuracy of Exchange-Correlation Functionals and Effect of Solvation on the Surface Energy of Copper. Phys. Rev. B 2013, 87 (24), 245402. https://doi.org/10.1103/PhysRevB.87.245402.

(6) Mathew, K.; Sundararaman, R.; Letchowrth-Weaver, K.; Arias, T. A.; Henning, R. G. Implicit Solvation Model for Density-Functional Study of Nanocrystal Surfaces and Reaction Pathways. J. Chem. Phys. 2014, 8, 084106. https://doi.org/10.1063/1.4865107.

(7) Lespes, N.; Filhol, J. S. Using Implicit Solvent in Ab Initio Electrochemical Modeling: Investigating $\mathrm{Li}^{+} / \mathrm{Li}$ Electrochemistry at a Li/Solvent Interface. J. Chem. Theory Comput. 2015, 11 (7), 3375-3382. https://doi.org/10.1021/acs.jctc.5b00170.

(8) Kopač Lautar, A.; Hagopian, A.; Filhol, J.-S. Modeling Interfacial Electrochemistry : Concepts and Tools. Submitted. 2019.

(9) Filhol, J.-S.; Neurock, M. Elucidation of the Electrochemical Activation of Water over Pd by First Principles. Angew. Chemie Int. Ed. 2006, 45 (3), 402-406. https://doi.org/10.1002/anie.200502540.

(10) Mamatkulov, M.; Filhol, J. S. An Ab Initio Study of Electrochemical vs. Electromechanical Properties: The Case of CO Adsorbed on a Pt(111) Surface. Phys. Chem. Chem. Phys. 2011, 13 (17), 7675-7684. https://doi.org/10.1039/c0cp01444c.

(11) Taylor, C. D.; Wasileski, S. A.; Filhol, J. S.; Neurock, M. First Principles Reaction Modeling of the Electrochemical Interface: Consideration and Calculation of a Tunable Surface Potential from Atomic and Electronic Structure. Phys. Rev. B 2006, 73, 165402. https://doi.org/10.1103/PhysRevB.73.165402.

(12) Lu, Z.; Schechter, A.; Moshkovich, M.; Aurbach, D. On the Electrochemical Behavior of Magnesium Electrodes in Polar Aprotic Electrolyte Solutions. J. Electroanal. Chem. 1999, 466, 203-217. https://doi.org/10.1016/S00220728(99)00146-1.

(13) Attias, R.; Salama, M.; Hirsch, B.; Gofer, Y.; Aurbach, D. Solvent Effects on the Reversible Intercalation of Magnesium-Ions into $\mathrm{V}_{2} \mathrm{O}_{5} \quad$ Electrodes. ChemElectroChem 2018, $5 \quad$ (22), 3514-3524. https://doi.org/10.1002/celc.201800932.

(14) Tamura, T.; Nakamura, M. Physicochemical Properties of Glyme - Li Salt Complexes as a New Family of RoomTemperature Ionic Liquids. Chem. Lett. 2010, 39, 753-755. https://doi.org/10.1246/cl.2010.753.

(15) Tobishima, S.; Morimoto, H.; Aoki, M.; Saito, Y.; Inose, T.; Fukumoto, T.; Kuryu, T. Glyme-Based Nonaqueous Electrolytes for Rechargeable Lithium Cells. Electrochim. Acta 2004, 49, 979-987. https://doi.org/10.1016/j.electacta.2003.10.009.

(16) Yoshida, K.; Nakamura, M.; Kazue, Y.; Tachikawa, N.; Tsuzuki, S.; Seki, S.; Dokko, K.; Watanabe, M. OxidativeStability Enhancement and Charge Transport Mechanism in Glyme À Lithium Salt Equimolar Complexes. J. Am. Chem. Soc. 2011, 133, 13121-13129. https://doi.org/10.1021/ja203983r. 